\title{
Immunofluorescent Studies in Adult Celiac Disease*
}

\author{
Walter Rubin, $\dagger$ Anthony Stephen Fauci, Marvin H. Sleisenger, and \\ GRAHAM H. JEFFries $\$$ WITH THE TEChNICAL ASSISTANCE OF \\ Sue MARGolis \\ (From the Department of Medicine, Cornell University Medical College, New York, N. Y.)
}

The etiology of childhood and adult celiac disease is not known. It has been established, however, that gluten, a complex heterogeneous protein in wheat and other cereal grains, plays a significant role in the pathogenesis of the disease, and that the harmful factor resides in gliadin, the alcohol soluble fraction of gluten $(1-4)$. Treatment of celiac disease with a gluten-free diet results in clinical and biochemical improvement usually accompanied by a decrease in the severity of the pathologic lesion in the proximal small intestinal mucosa. The ingestion of gluten by patients in remission on a gluten-free diet causes an exacerbation of symptoms, accompanied by malabsorption and acute inflammatory changes in the proximal jejunal mucosa (5). Furthermore, direct instillation of flour or gluten into the histologically normal distal small intestine of patients with adult celiac disease produces similar acute mucosal inflammation (6), whereas the intestinal mucosa of a normal subject remains unchanged. The toxicity of gluten and gliadin is retained by mixtures of straight chain polypeptides that result from enzymatic and chemical digestion of the protein (7-9). Further digestion of these toxic peptides by fresh extracts of hog small intestinal mucosa or by crude papain renders them inactive $(7,8)$. Deamidation or complete acid hydrolysis of gliadin also renders it inactive (1).

\footnotetext{
* Submitted for publication August 24, 1964 ; accepted November 27, 1964.

Supported by the John A. Hartford Foundation and by grant no. CA 09386 from the National Cancer Institute, U. S. Public Health Service.

$\dagger$ U. S. Public Health Service trainee, National Institute of Arthritis and Metabolic Diseases, grant no. TI AM 5430. Address requests for reprints to: Dr. Walter Rubin, The New York Hospital-Cornell Medical Center, 525 East 68th St., New York, N. Y. 10021.

$\ddagger$ U. S. Public Health Service Research Career Development Awardee, National Institute of Arthritis and Metabolic Diseases, grant no. 5-K3-AM-14,153.
}

Two hypotheses of the mechanism of gluten toxicity in celiac patients have been proposed (3). One hypothesis is that celiac disease is the result of an inborn error of metabolism-a deficiency of a specific peptidase in the intestinal mucosa, which results in the accumulation of indigestible toxic peptides of gliadin. Two recent observations, however, have failed to demonstrate a specific peptidase deficiency in the small intestinal mucosa of celiac patients $(10,11)$.

The second hypothesis suggests that celiac disease may be immunologic: a local hypersensitivity reaction to gluten or to a gluten peptide. Several observations support this theory. Patients with adult celiac disease often benefit clinically and biochemically from adrenocorticosteroid therapy (12). Celiac patients on a gluten-free diet have occasionally reacted dramatically to the ingestion of minute quantities of gluten: such a response has been called "gliadin shock" (13). The infiltration of the small intestinal mucosa in celiac disease with plasma cells, lymphocytes, macrophages, and eosinophils is consistent with a local hypersensitivity reaction. In recent years, humoral antibodies to wheat gluten and gluten fractions have been found in the sera of both children and adults with celiac disease, in greater frequency and titer than in normal controls. These antibodies have been demonstrated by complement fixation (14), immunodiffusion $(15,16)$, and erythrocyte agglutination techniques (16-18). It is questionable, however, that humoral antigliadin antibodies are of primary etiologic importance in celiac disease, since celiac patients have also exhibited a higher incidence of humoral antibodies to the milk proteins, casein, lactalbumin, and beta lactoglobulin (15-18). Furthermore, there have been descriptions of acquired agammaglobulinemia in adult celiac disease (19). Skin tests to gluten and its fractions have been negative in celiac patients, and peripheral eosinophilia and a 
personal or family history of allergy are unusual $(2,20)$.

Recent observations by Malik, Watson, Murray, and Cruickshank (21) suggested the presence of a humoral autoantibody to small intestinal epithelium in untreated patients with adult celiac disease. Using the indirect immunofluorescent technique, and a fluoresceinated antiserum to the human alpha and beta globulins, they demonstrated a reaction between fresh sera from untreated celiac patients and the cytoplasm of unfixed autologous jejunal mucosa, particularly in the crypts of Lieberkuhn. They obtained similar results with homologous and even monkey jejunum.

To investigate further the possibility that immunologic processes play a role in the pathogenesis of adult celiac disease, duodenal and jejunal biopsies from patients with adult celiac disease were studied by immunofluorescent techniques. These studies were planned to determine: 1 ) whether immunoglobulins are present in these tissues; 2) whether gliadin is bound by these immunoglobulins or to any component of the intestinal mucosa ; 3) whether complement is fixed in vivo in the mucosa as evidenced by the presence of beta $_{1 \mathrm{c}}$ globulin component of human complement $(22)$; 4) whether immune complexes or gamma globulin aggregates can be identified in the tissues by their in vitro fixation of complement both with or without preincubation with gliadin; 5) whether an immunoglobulin in the serum from celiac patients reacts with autologous intestinal mucosa.

\section{Methods}

Duodenal and jejunal biopsies were obtained with a peroral hydraulic multiple biopsy tube from nine patients with adult celiac disease (23). Two of these patients (D.R. and P.T.) had been undiagnosed previously and were untreated at the time of the study. In seven patients, a diagnosis of adult celiac disease had been based on clinical and biochemical evidence of malabsorption and total villous atrophy of the proximal jejunal mucosa, together with clinical and biochemical improvement with a gluten-free diet. These patients had been on diet therapy for periods of 3 to 7 years. On careful questioning, however, only three of these seven patients had adhered strictly to the gluten-free diet; the other four admitted to the regular ingestion of varying amounts of gluten-containing foods.

The biopsy specimens were embedded in $7.5 \%$ gelatin as described by Burkholder, Littell, and Klein (24), were frozen within 1 to 3 minutes in an acetone-dry ice bath at $-70^{\circ} \mathrm{C}$, and were stored at $-20^{\circ} \mathrm{C}$ in sealed plastic bags to prevent dehydration. Other biopsy specimens from each patient were fixed in $10 \%$ neutral formalin, and paraffin sections were stained with hematoxylin and eosin and with the periodic acid-Schiff stains. Serum obtained from each patient was used immediately or stored at $-20^{\circ} \mathrm{C}$.

Tests performed at the time of the biopsy study to assess small intestinal function included chemical analysis of fat in a 3-day stool collection, and the measurement of 5-hour urinary excretion of $\mathrm{D}$-xylose after a $25-\mathrm{g}$ oral dose. Table I summarizes the findings in each patient. The fecal fat absorption and D-xylose absorption had returned to normal in the three patients who had followed a strict gluten-free diet for periods of 3 to 5 years. The jejunal mucosa had returned to normal in one patient (K.D.), whereas in the other two patients (P.R. and J.T.), dissecting and light microscopy revealed a leaf-like villous structure with persisting inflammatory cell infiltration. Of the four patients who

TABLE I

Celiac patients

\begin{tabular}{|c|c|c|c|c|c|c|c|c|}
\hline Patient & Sex & Age & $\begin{array}{l}\text { Duration } \\
\text { of symp- } \\
\text { toms }\end{array}$ & $\begin{array}{l}\text { Duration of } \\
\text { diet therapy }\end{array}$ & $\begin{array}{l}\text { Adherence to } \\
\text { gluten-free } \\
\text { diet }\end{array}$ & $\begin{array}{l}\text { Fecal } \\
\text { fat } \\
\text { excretion* }\end{array}$ & $\begin{array}{l}\text { D-Xylose } \\
\text { absorp- } \\
\text { tiont }\end{array}$ & $\begin{array}{c}\text { Jejunal } \\
\text { pathology }\end{array}$ \\
\hline & & & $y r s$ & $y r s$ & & & & \\
\hline 1. D.R. & $\mathrm{F}$ & 35 & 19 & Untreated & Untreated & 29 & 2.4 & Severe \\
\hline 2. P.T. & M & 55 & 5 & Untreated & Untreated & $12.7 \ddagger$ & 3.6 & Severe \\
\hline 3. R.C. & $\mathrm{F}$ & 49 & 23 & 7 & No & 13 & 6.3 & Moderate \\
\hline 4. O.M. & $\mathrm{F}$ & 64 & 22 & 5 & No & 15 & 1.3 & Moderate \\
\hline 5. W.S. & $\mathrm{M}$ & 32 & 29 & 5 & No & 4 & 5.4 & Moderate \\
\hline 6. M.D. & $\mathrm{F}$ & 55 & 18 & 4 & Noß & 3 & 3.1 & Mild \\
\hline 7. J.T. & M & 50 & 4 & 4 & Yes & 3 & 8.1 & Mild \\
\hline 8. P.R. & $\mathrm{M}$ & 54 & 3 & 3 & Yes & 3 & 5.9 & Mild \\
\hline 9. K.D. & $\mathrm{F}$ & 38 & 5 & 5 & Yes & 2 & 6 & Normal \\
\hline
\end{tabular}

* Grams per day from a 3-day stool collection. Normal is less than 5 .

† Grams excreted in 5-hour urine collection after ingestion of $25 \mathrm{~g}$. Normal is greater than 4.0.

$\ddagger$ Collection obtained while the patient was on a low fat intake.

$\S$ Patient was also on prednisolone, $12.5 \mathrm{mg}$ per day. 
TABLE II

Control subjects

\begin{tabular}{lccl}
\hline \hline Patient & Sex & Age & \multicolumn{1}{c}{ Diagnosis } \\
\hline 1. D.R. & M & 56 & Scleroderma with steatorrhea \\
2. E.I. & M & 39 & Regional ileitis \\
3. B.S. & M & 66 & Pancreatic steatorrhea \\
4. H.R. & F & 50 & Pernicious anemia \\
5. A.G. & M & 49 & Alcoholic gastritis \\
\hline
\end{tabular}

had not adhered to strict diets, three (R.C., O. M., and W.S.) revealed moderately severe changes in the intestinal mucosa with epithelial convolutions, cellular infiltration, and superficial epithelial cell damage. The fecal fat excretion or D-xylose absorption, or both, were abnormal in two of these patients. The fourth patient (M.D.), who had also received adrenocorticoid therapy, showed mild mucosal changes and an abnormal D-xylose test. The two untreated patients showed total villous atrophy of the jejunal mucosa with marked inflammatory cell infiltration and surface epithelial cell damage; each had malabsorption. Control jejunal biopsies and sera were obtained similarly from five patients with other diseases (Table II).

The following antisera were obtained from commercial laboratories: 1) rabbit antihuman gamma globulin, $^{1}$ 2) goat antihuman gamma ${ }_{1 a}$ globulin (beta $a_{2 a}$ globulin), ${ }^{1}$ 3) goat antihuman gamma ${ }_{1 м}$ globulin (beta $a_{2 M}$ globulin), 4) goat antihuman beta ${ }_{1 c} /$ beta $_{1 a}$ globulin,1 5) rabbit antihuman albumin, ${ }^{1}$ 6) rabbit antihuman fibrinogen, ${ }^{1}$ 7) rabbit antibovine serum albumin, ${ }^{1}$ 8) rabbit anticasein, ${ }^{2}$ and 9) rabbit antiovalbumin. ${ }^{2}$ A second rabbit antihuman beta beta $_{1 \mathrm{c}}$ globulin was kindly supplied by Dr. Hans J. Müller-Eberhard. ${ }^{3}$

Each antiserum was tested against its respective antigen by means of double immunodiffusion in Ouchterlony plates using $1.5 \%$ agar in a $\mathrm{pH} 7.4,0.11 \mathrm{M}$ phosphate buffer and/or by immunoelectrophoresis in $1.5 \%$ agar in a $\mathrm{pH} 8.2,0.077 \mathrm{M}$ barbital buffer. The number of precipitin bands produced by each antiserum, the cross reactivity of various antisera, and the position of precipitin bands on immunoelectrophoresis were noted. Fresh human serum was used to test antisera to human plasma protein fractions. One per cent solutions of twice crystallized bovine serum albumin 2 or twice crystallized egg albumin ${ }^{2}$ in $\mathrm{pH} 7.4,0.01 \mathrm{M}$ phosphate-buffered saline (PBS), and a saturated solution of casein ${ }^{2}$ in PBS were used to test their respective antisera. Antisera to gammarm globulin and to beta ${ }_{1 \mathrm{c}} /$ beta $_{1 \mathrm{a}}$ globulin produced a single precipitin band on immunodiffusion plates and immunoelectrophoresis. Antisera to gamma 2 globulin and gamma $_{1 a}$ globulin produced two precipitin bands that showed partial identity. On immunoelectrophoresis the antisera to the immunoglobulins produced precipitin bands that occupied their characteristic positions.

1 Hyland Laboratories, Los Angeles, Calif.

2 Nutritional Biochemicals Corp., Cleveland, Ohio.

${ }^{3}$ Scripps Clinic and Research Foundation, La Jolla, Calif.
A rabbit antigliadin antiserum was produced in the following manner: $150 \mathrm{mg}$ of gliadin ${ }^{2}$ was suspended in $1 \mathrm{ml}$ of saline, thoroughly mixed with $1 \mathrm{ml}$ of complete Freund's adjuvant,4 and injected intramuscularly into each of four female New Zealand white rabbits. Each rabbit received booster injections every 3 to 4 weeks. They were bled 10 days after each injection, and their sera were tested for antigliadin antibody by precipitin tests in test tubes and by immunodiffusion on Ouchterlony plates against a saturated solution of gliadin in PBS. The antiserum used in this study had a precipitating titer of $1: 64$ and formed 4 bands against gliadin in an Ouchterlony plate (Figure 1).

Preparation of fluorescein conjugates. A crude globulin fraction was precipitated from each antiserum by the slow addition of $18 \mathrm{ml}$ of $20 \% \mathrm{Na}_{2} \mathrm{SO}_{4}$ to each $2 \mathrm{ml}$ of serum at $4^{\circ} \mathrm{C}$. The mixture was incubated for an hour at $37^{\circ} \mathrm{C}$, and the globulin precipitate, separated by centrifugation, was washed three times with $18 \% \quad \mathrm{Na}_{2} \mathrm{SO}_{4}$. All further preparative procedures were carried out in a constant temperature room at $4^{\circ} \mathrm{C}$. The washed globulin precipitate was dissolved in normal saline equal to the original volume of antiserum and was dialyzed against saline until sulfate could no longer be detected in the external saline upon the addition of a saturated solution of $\mathrm{BaCl}_{2}$. The dialyzate was then centrifuged, and the protein concentration of the clear supernatant was determined from its absorption at $280 \mathrm{~m} \mu$ in a Zeiss spectrophotometer; a standard curve for protein

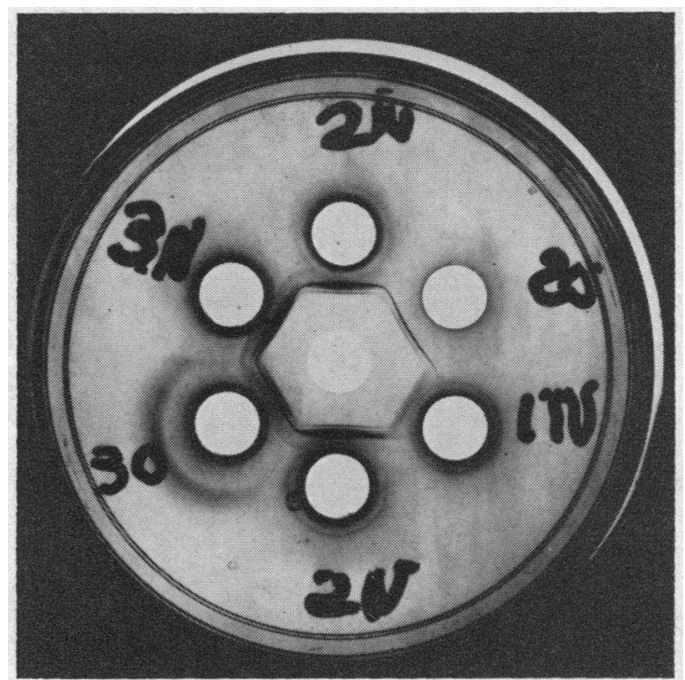

Fig. 1. Precipitin bands produced by antigliadin ANTISERA IN OUCHTERLONy plates. A saturated solution of gliadin in phosphate-buffered saline (PBS), $\mathrm{pH}$ 7.4, had been placed in the central well. Antisera from three separate rabbits (no. 1 to 3 ) were drawn on two different dates (designated as $\mathrm{O}$ and $\mathrm{N}$ ) and were placed in the surrounding wells. The antiserum in well 30 , which produced 4 precipitin bands, was used in the fluorescent studies.

\footnotetext{
${ }^{4}$ Difco Laboratories, Detroit, Mich.
} 
concentration had been derived from saline solutions of plasma Fraction II. ${ }^{1}$ The solution of antiserum was finally diluted with normal saline and with a $\mathrm{Na}_{2} \mathrm{CO}_{3}$ $\mathrm{NaHCO}_{3}$ buffer $(0.05 \mathrm{M}, \mathrm{pH} 9.0)$ to a final solution containing $1 \%$ of protein and $10 \%$ by volume of buffer. This buffer was added slowly with constant stirring.

Fluorescein isothiocyanate, ${ }^{5}$ dissolved in dry acetone, was added slowly with constant stirring to the buffered globulin solution; $0.035 \mathrm{mg}$ of fluorescein isothiocyanate was added to each milligram of protein in solution while the volume of added acetone did not exceed $10 \%$ of the volume of protein solution. This mixture was stirred continuously for 18 hours at $4^{\circ} \mathrm{C}$ and then dialyzed against several changes of phosphate buffer, $0.01 \mathrm{M}, \mathrm{pH}$ 7.2. The dialyzate was filtered through a column of Sephadex-G-25 medium, ${ }^{6}$ which had been suspended in the same phosphate buffer. The first yellow zone eluted from the Sephadex column with $0.01 \mathrm{M}$, pH 7.2 phosphate buffer was concentrated by dialysis against polyvinylpyrrolidone ${ }^{7}$ in $\mathrm{PBS}$ to a volume approximating that of the original antiserum and was then dialyzed against PBS alone for several hours. This fluoresceinated protein conjugate was centrifuged; Thimerosal 8 1:10,000 was added to the clear supernatant, and the solution was sterilized by filtration through a Millipore filter ${ }^{9}$ and stored at $4^{\circ} \mathrm{C}$.

Several of the fluorescein conjugates eluted from the Sephadex columns were placed on packed columns of DEAE cellulose, ${ }^{10}$ equilibrated with $0.01 \mathrm{M}, \mathrm{pH} 7.2$ phosphate buffer, and eluted with a $0.1 \mathrm{M}, \mathrm{pH} 6.3$ phosphate buffer (25). The yellow-green fluoresceinated protein conjugates detected by absorption at $280 \mathrm{~m} \mu$ and $490 \mathrm{~m} \mu$ in a Zeiss spectrophotometer appeared as a sharp peak within the first $200 \mathrm{ml}$ of eluate. The pooled $10-\mathrm{ml}$ fractions containing these fluoresceinated globulin conjugates were concentrated by ultrafiltration in collodion bags ${ }^{11}$ to the volume of the original antiserum. They were dialyzed against several changes of PBS and were sterilized and stored at $4^{\circ} \mathrm{C}$ as described previously.

Each fluoresceinated antibody conjugate was tested against its corresponding antigen by double immunodiffusion in Ouchterlony plates or by immunoelectrophoresis, or both. The precipitin bands thus obtained were generally much lighter than those produced by the corresponding unconjugated antiserum, but were readily visible under ultraviolet light. Just before use, conjugates were absorbed for 1 hour at room temperature with guinea pig liver powder, ${ }^{12} 100 \mathrm{mg}$ of powder for each milliliter of conjugate. A second absorption was sometimes required for optimal reduction of nonspecific staining. Each conjugate was further diluted with PBS

\footnotetext{
5 Baltimore Biological Laboratories, Baltimore, Md.

6 Pharmacia Fine Chemicals, Inc., Rochester, Minn.

7 Matheson, Coleman and Bell, East Rutherford, N. J.

8 Eli Lilly and Co., Indianapolis, Ind.

${ }^{9}$ Millipore Filter Corp., Bedford, Mass.

10 Mann Research Laboratories, Inc., New York, N. Y.

11 Carl Schleicher and Schuell Co., Keene, N. H.

12 The Sylvana Co., Millburn, N. J.
}

according to the intensity of its fluorescent staining to further reduce nonspecific staining.

Preparation and staining of tissue sections. Sections $6 \mu$ in thickness were cut from the frozen tissues in an International-Harris cryostat 13 at $-20^{\circ} \mathrm{C}$, were placed on glass microscope slides, and air dried for 10 to 20 minutes at room temperature. Some sections were fixed in acetone for 10 minutes at room temperature, others were fixed in $95 \%$ ethanol at room temperature for 30 minutes, while others remained unfixed. After fixation the slides were again air-dried for 10 to 30 minutes at room temperature, stored at $4^{\circ} \mathrm{C}$, and used within 36 hours.

Staining of the sections with fluoresceinated antibodies was carried out as follows. The slides were first washed for 15 minutes in three changes of PBS. Both fixed and unfixed tissue sections from each biopsy were then incubated with solutions of antigen or fluoresceinated antisera, or both. Solutions of antigen or human sera ( 2 to 4 drops) were incubated with sections at $37^{\circ} \mathrm{C}$ for 30 minutes in a moist chamber. Fluoresceinated antibodies ( 2 to 4 drops) were incubated with sections at room temperature for 30 minutes in a moist chamber. After each incubation with either antigen, human serum, or a fluoresceinated antiserum, each slide was washed for 30 minutes in three changes of PBS. After the final washing, sections were mounted in $0.025 \mathrm{M}, \mathrm{pH} 7.4$ phosphate-buffered glycerol and covered with a glass cover slip.

The slides were studied within 24 hours of staining with a Zeiss fluorescence microscope, ${ }^{14}$ using an Osram 200 mercury arc, one BG12 exciter filter, a dark field condenser, and a Zeiss no. 53 barrier filter. Colored photomicrographs of areas of interest were obtained concomitantly with Anscochrome T/100 tungsten film. ${ }^{15}$ Exposure times of $1 \frac{1}{2}$ to $2 \frac{1}{2}$ minutes were usually required.

Whenever a fluoresceinated antibody produced positive fluorescence, the tissue sections were restudied by repeating the same incubations, but with the added control of diluting the fluoresceinated antibody with its respective unconjugated antiserum to the same final concentration and noting thereby the degree of inhibition of the fluorescent staining.

The following studies were carried out with both fixed and unfixed tissue sections.

A. To determine the distribution of immunoglobulins. Sections were incubated with the following fluoresceinated antisera: 1) rabbit antihuman gamma 2 globulin antiserum, 2) goat antihuman gamma $a_{1 a}$ globulin antiserum, 3) goat antihuman gamma 1 globulin antiserum, 4) rabbit antihuman fibrinogen antiserum, and 5) rabbit antihuman albumin antiserum.

B. To study the interaction of dietary antigens with the mucosa. Sections were incubated with the following

\footnotetext{
13 International Equipment Co., Needham Heights, Mass.

${ }^{14}$ Carl Zeiss, Germany.

15 Ansco Photo Products of General Aniline and Film Corp., Binghamton, N. Y.
} 
antigens and fluoresceinated antisera: 1) rabbit antigliadin antiserum, 2) a saturated solution of gliadin in PBS, followed by rabbit antigliadin antiserum, 3) rabbit antibovine serum albumin antiserum, 4) a $1 \%$ solution of crystalline bovine serum albumin in PBS, followed by rabbit antibovine serum albumin antiserum, 5) rabbit anticasein antiserum, 6) a saturated solution of casein in PBS, followed by rabbit anticasein antiserum, 7) rabbit antiovalbumin antiserum, and 8 ) a $1 \%$ solution of crystalline ovalbumin in PBS, followed by rabbit antiovalbumin antiserum.

C. To study the distribution of in vivo and or in vitro fixed complement in the mucosa. Sections were incubated with the following antigens, sera, and fluoresceinated antisera: 1) goat or rabbit antihuman beta $_{1 \mathrm{c}} / \mathrm{beta}_{1 \mathrm{a}}$ globulin antiserum, 2) fresh autologous serum, followed by rabbit or goat antihuman beta ${ }_{1 c} /$ beta $_{12}$ globulin antiserum, 3) autologous serum, inactivated by heating at $56^{\circ} \mathrm{C}$ for 30 minutes, followed by rabbit or goat antihuman beta $_{1 \mathrm{c}} /$ beta $_{1 \mathrm{a}}$ globulin antiserum, 4) a saturated gliadin solution in PBS, followed by fresh autologous serum, followed by rabbit or goat antihuman beta ${ }_{1 c} /$ beta $_{1 \mathrm{a}}$ globulin antiserum, and 5) a saturated gliadin solution in PBS, followed by unconjugated rabbit antigliadin antiserum, followed by fresh autologous serum, followed by rabbit or goat antihuman beta ${ }_{1 \mathrm{c}} /$ beta $_{1 \mathrm{a}}$ globulin antiserum.

D. To test for humoral autoantibodies to jejunal mucosal antigens. Sections from four of the five control patients and from six of the nine celiac patients were incubated with autologous serum and were then incubated with the following fluoresceinated antisera: 1) rabbit antihuman gamma 2 globulin antiserum, 2) goat antihuman gamma $_{1 \text { a }}$ globulin antiserum, and 3) goat antihuman gamma $_{1 M}$ globulin antiserum.

In addition, unfixed sections from the jejunal biopsy of one of the untreated celiac patients (P.T.) of blood group $\mathrm{O}, \mathrm{Rh}^{+}$, were incubated with fresh sera from six normal control subjects, with the sera from each of the other celiac patients, and with the sera from two additional patients with untreated celiac disease, from whom fresh frozen tissues had not been available. The sections were then incubated with fluoresceinated antisera to each of the human immunoglobulins as described above.

\section{Results}

A. Distribution of the immunoglobulins. Immunoglobulins were confined to the cytoplasm of mononuclear cells in the lamina propria of all small intestinal sections that were studied, in the five control patients as well as in the nine patients with celiac disease (Figure 2 ). The acetone-fixed sections were the most satisfactory, both with regard to the preservation of cell morphology and to the consistency and brightness of their immunofluorescence. The fixation, however, caused some tissue dehydration, and therefore the tissue density
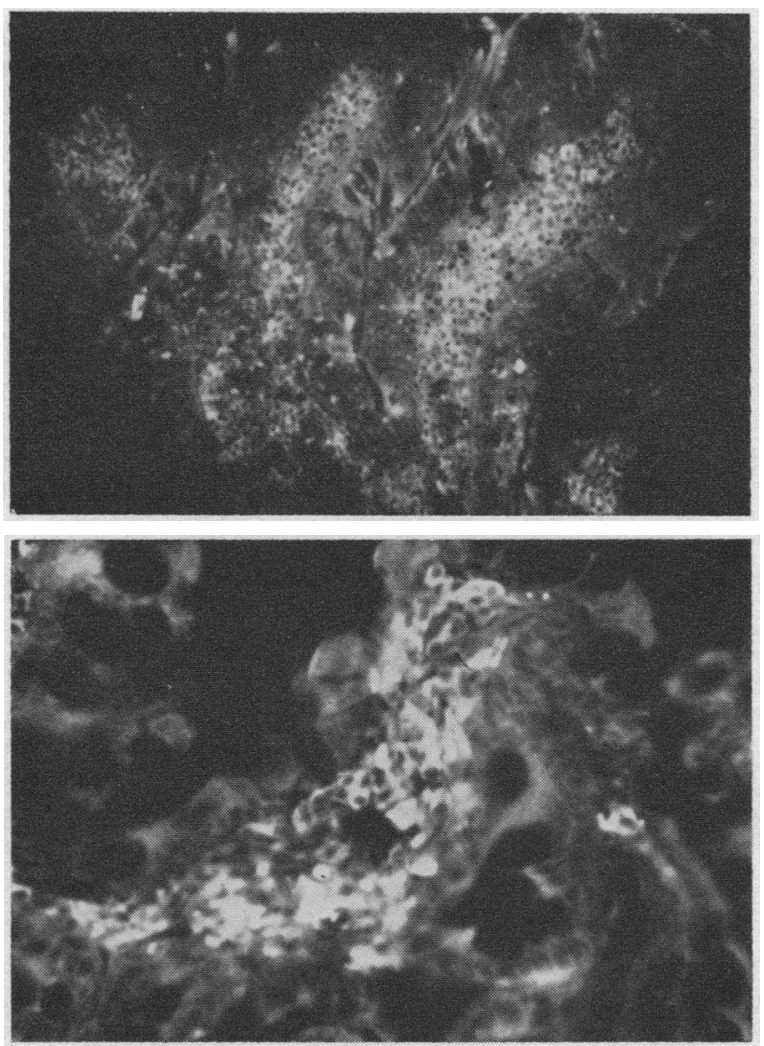

Fig. 2, A and B. Fluorescent staining of the imMUNOGLOBULINS. These acetone-fixed sections were stained directly with the fluoresceinated goat antihuman gamma $_{1 a}$ globulin antibody. Brilliant fluorescence resulted in the majority of mononuclear cells in the lamina propria. The density of these cells appears increased, due to tissue dehydration. Most of the fluorescent cells appear to be plasma cells. The epithelium remains unstained. Figure 2A shows the normal villi of control patient B.S. (magnification $150 \times$ ). Figure 2B shows the jejunum from celiac patient R.C. (magnification $375 \times)$.

of these fluorescent cells appeared much greater, even in the normal specimens, than they did in the formalin-fixed, hematoxylin- and eosin-stained sections. The identity of these fluorescent cells could not always be determined. Many contained smooth, abundant cytoplasm with eccentric round nuclei and thus appeared to be plasma cells. Others were larger cells, with abundant granular cytoplasm and oval nuclei, and were thought to be macrophages. Still others had the appearance of small lymphocytes with a rim of fluorescent cytoplasm around a spherical nucleus. Eosinophils, which were abundant in the biopsies from celiac patients, were a constant source of non- 

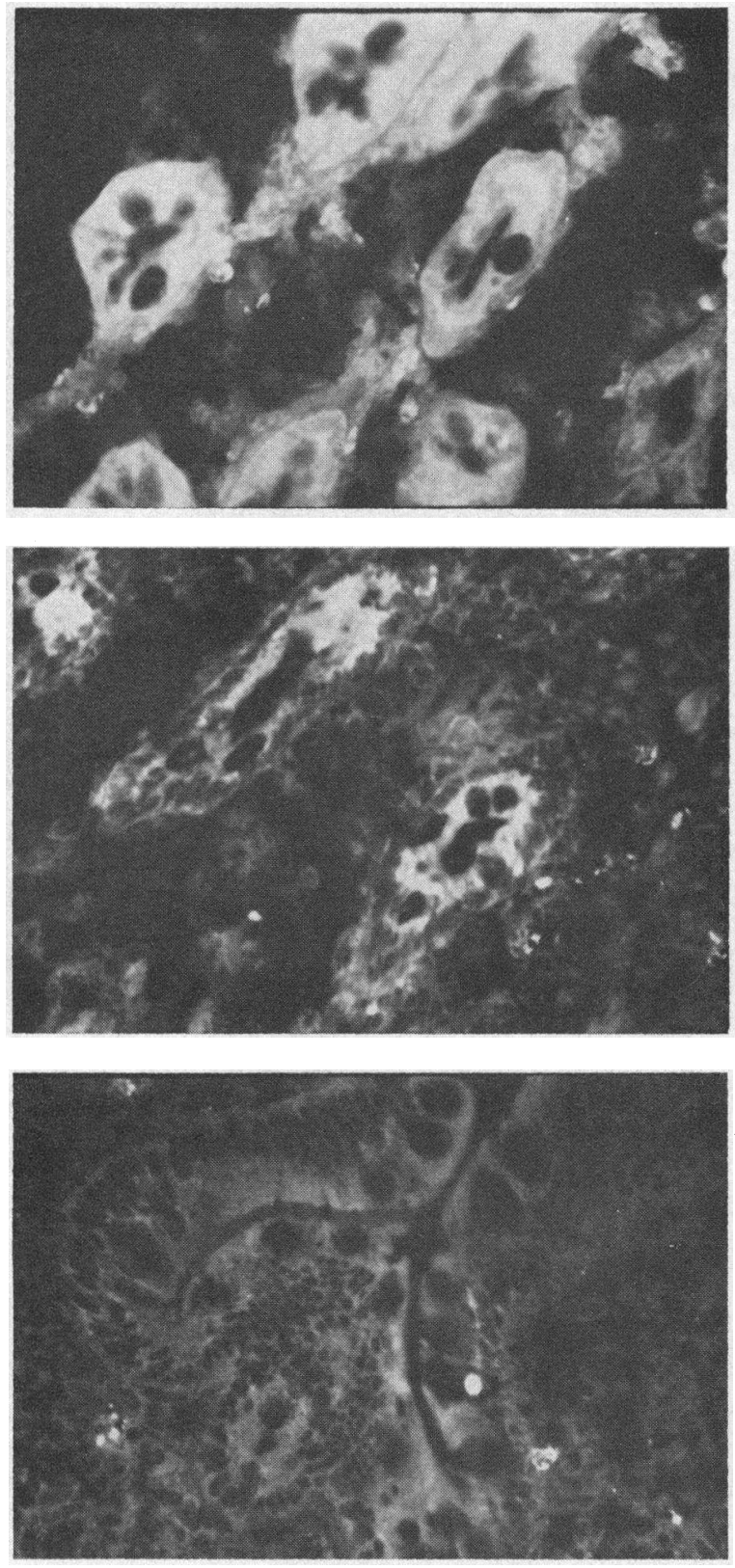

Fig. 3, A-C. Gliadin binding by the jejunal epiTHElium in patients With adult Celiac disease. Acetone-fixed sections from two patients with adult celiac disease, W.S. (A) and P.T. (B), were first incubated with a saturated solution of gliadin in PBS, washed, and then stained with fluoresceinated rabbit antigliadin antibody. Fluorescence was observed in the cytoplasm of the epithelium, especially in the crypt cells, which are demonstrated here (magnification $375 \times$ ). Sections from control patient B.S. (C), treated similarly, revealed no fluorescence in the epithelium (magnification $375 \times$ ). specific bright fluorescence, which did not progressively fade during ultraviolet illumination, in contrast to the fading of the specific immunofluorescence of mononuclear cells.

Antihuman gamma $\mathbf{1 a}_{\mathbf{a}}$ globulin fluoresceinated antiserum uniformly produced the most intense staining of the majority of the mononuclear cells in the lamina propria (Figure 2). This bright fluorescence was markedly inhibited by diluting the fluoresceinated antiserum with unconjugated antihuman gamma ${ }_{1 \mathrm{a}}$ globulin antiserum. Although the precipitin bands formed by this antiserum and human serum on Ouchterlony plates showed partial identity to those produced with antihuman gamma $_{2}$ globulin antiserum, no inhibition of tissue staining resulted when the fluoresceinated antihuman gamma ${ }_{1 a}$ globulin antiserum was similarly diluted with unconjugated antihuman gamma globulin or gamma ${ }_{\text {IM }}$ globulin antisera. Fluoresceinated antihuman gamma ${ }_{2}$ globulin and antihuman gamma ${ }_{I M}$ globulin antisera stained a considerably smaller number of mononuclear cells in the lamina propria.

The fluoresceinated antisera to the inmunoglobulins produced no fluorescence in the epithelial cells of mucosae from control subjects or patients with celiac disease.

Fluorescent staining for albumin and fibrinogen produced inconsistent results, but often, especially with alcohol-fixed sections, revealed irregular, small particles of material in the lamina propria. These were thought to represent denatured aggregates of these proteins in the interstitial fluid of the lamina propria.

TABLE III

Immunofuorescent staining of jejunal epithelium of celiac patients with antigliadin antibody

\begin{tabular}{lll}
\hline Patient & $\begin{array}{c}\text { Tissue plus fluores- } \\
\text { ceinated antigliadin } \\
\text { antibody* }\end{array}$ & $\begin{array}{c}\text { Tissue plus gliadin plus } \\
\text { fluoresceinated anti- } \\
\text { gliadin antibody }\end{array}$ \\
\hline 1. D.R. & No cytoplasmic staining & $3+$ cytoplasmic staining \\
2. P.T. & No cytoplasmic staining & 2+ cytoplasmic staining \\
3. R.C. & No cytoplasmic staining & $2+$ cytoplasmic staining \\
4. O.M. & 2+ cytoplasmic staining & $3+$ cytoplasmic staining \\
5. W.S. & 2+ cytoplasmic staining & $3+$ cytoplasmic staining \\
6. M.D. & No cytoplasmic staining & $1+$ cytoplasmic staining \\
7. J.T. & 2+ cytoplasmic staining & $3+$ cytoplasmic staining \\
8. P.R. & No cytoplasmic staining & $2+$ cytoplasmic staining \\
9. K.D. & No cytoplasmic staining & $1+$ cytoplasmic staining \\
\hline
\end{tabular}

* Degree of fluorescent staining is rated subjectively from 0 to $3+$ both from direct examination with the fluorescent microscope and from photomicrographs. 
B. The interaction of dietary antigens with the intestinal mucosa. When the small intestinal sections were first incubated with gliadin in solution and then stained with antigliadin antibody, fluorescence was observed in the cytoplasm of epithelial cells of all nine patients with adult celiac disease (Figure 3, A-B, Table III). Of the five control patients (Figure 3, C) only one (A.G., alcoholic gastritis) demonstrated such epithelial cell staining, of an intensity approximately equal to that of the most weakly stained mucosa from a celiac patient (K.D.). This fluorescence was generally maximal in the crypt epithelium, but the villous epithelium was also stained. Acetonefixed sections again produced the most satisfactory results, although epithelial staining could also be demonstrated with unfixed tissue.

Direct staining of small intestinal sections with fluoresceinated antigliadin antiserum, without preincubation with gliadin, produced no staining of mucosae from control subjects. Three celiac patients, however, one of whom supposedly followed a strict gluten-free diet, demonstrated such epithelial staining, but to a lesser degree than was observed when the respective sections were preincubated with gliadin solution (Table III).

When sections from control subjects, or from celiac patients, were preincubated with bovine serum albumin, casein, or ovalbumin solutions, and were then stained with the corresponding fluoresceinated antisera, or when they were stained directly with these antisera, fluorescent staining was not observed.

The epithelial cell staining with fluoresceinated antigliadin antiserum, after incubation with gliadin solution, could not be significantly inhibited by diluting the fluoresceinated antigliadin antiserum with unconjugated antiserum. This fluorescent staining was markedly inhibited, however, when the fluoresceinated antigliadin antiserum was first absorbed with gliadin (100 $\mathrm{mg}$ of gliadin per 1 $\mathrm{ml}$ of antiserum) for 1 hour at room temperature. This control was carried out in sections from only four of the celiac patients.

No fluorescence of the inflammatory cells of the lamina propria was observed when sections were stained either directly with fluoresceinated antigliadin antiserum or after incubation with gliadin solution. Thus gliadin did not appear to be

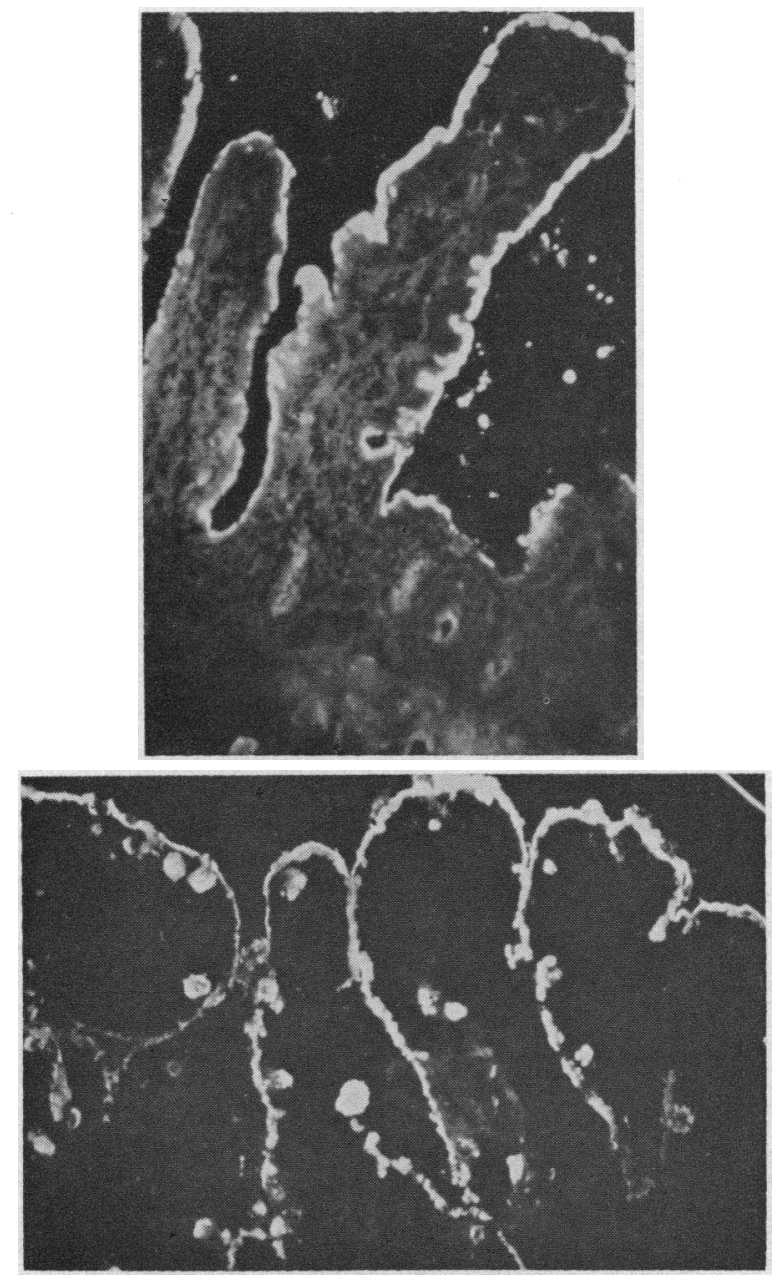

Fig. 4, A And B. Complement fixation in the Jejunal mucosa. Acetone-fixed sections were incubated with fresh autologous serum, washed, and then stained with fluoresceinated antihuman beta 1 c $/$ beta $_{1 \mathrm{a}}$ globulin antibody. Brilliant fluorescence, indicating the in vitro fixation of this component of complement, is observed along the superficial margin of the epithelial cells, both on the villi and in the crypts. A. Normal villi and crypts of control patient E.I. (magnification $150 \times$ ). B. Section from celiac patient M.D., who had shown mild pathologic changes. The distribution of staining is similar to that of the control. The vacuoles of the goblet cells often appear stained (magnification $150 \times$ ).

the antigen against which the immunoglobulins in these cells were directed.

C. Complement studies. Direct staining of the sections with either of the fluoresceinated antihuman beta $_{1 \mathrm{c}} /$ beta $_{1 \mathrm{a}}$ globulin antibodies produced no specific fluorescence. Thus there was no evidence that complement had been fixed to the mucosae in vivo. When sections from both con- 
trol and celiac patients were first incubated with fresh autologous or homologous serum and then stained with fluoresceinated antihuman beta $1 \mathrm{c} /$ beta $_{1 \mathrm{a}}$ globulin antibodies, a brilliant fluorescence was uniformly observed along the superficial margin of the epithelial cells, both on the villi and extending into the crypts (Figure 4, A-B). Moreover, often the vacuoles of the goblet cells were also stained. This distribution of fluorescence appeared to correspond to the distribution of mucin as demonstrated by the periodic acid-Schiff staining of formalin-fixed sections. Acetone-fixed sections once more proved to be the most satisfactory, although again this staining could be demonstrated in unfixed sections. This brilliant fluorescence could not be inhibited by diluting the fluoresceinated antihuman beta $_{1 \mathrm{c}} /$ beta $_{1 \mathrm{a}}$ globulin antiserum with unconjugated antiserum, a phenomenon suggesting the presence of a large number of

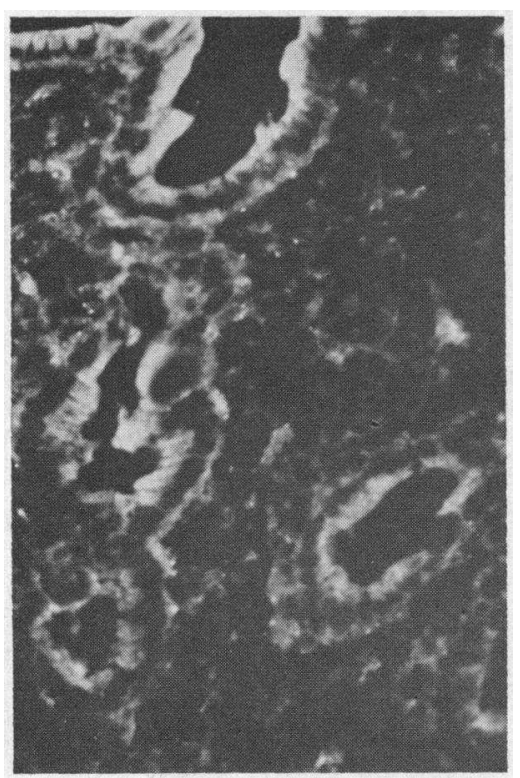

Fig. 5. Reaction of intestinal mucosa with aUTOLOGOUS SERUM. This unfixed section from untreated celiac patient P.T. had been incubated with fresh autologous serum, washed, and then stained with fluorescei-

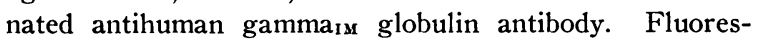
cence of the superficial aspects of the epithelial cells resulted, both along the atrophic surface and in the crypts. Control patients, however, demonstrated the same re-

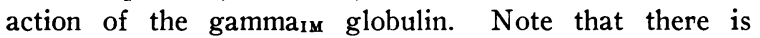
little staining of the cells of the lamina propria. Acetone-fixed sections generally yielded better staining of gamma $_{1 \mathrm{~m}}$ globulin in certain of the mononuclear inflammatory cells as well. antigen molecules. If the sections, however, were preincubated with serum, in which complement had been inactivated by heating at $56^{\circ} \mathrm{C}$ for 30 minutes, almost no fluorescence was observed on subsequent staining with the fluoresceinated antibody.

No fixation of beta ${ }_{1 \mathrm{c}}$ globulin could be demonstrated in vitro in the cells of the lamina propria. Thus, there was no evidence of complement-fixing antigen-antibody complexes or of gamma globulin aggregates in the macrophages or other inflammatory cells. Moreover, when sections were stained for beta $_{1 \mathrm{c}} /$ beta $_{1 \mathrm{a}}$ globulin after sequential incubation with gliadin solution, and fresh autologous serum, fluorescence was limited again to the superficial margin of the epithelial cells and goblet cells; the mononuclear cells of the lamina propria remained unstained. Thus no binding of gliadin in complement-fixing antigen-antibody complexes could be demonstrated.

D. Studies to detect humoral autoantibodies reacting with intestinal epithelial cells. When jejunal mucosal sections from six of the celiac patients had been preincubated with autologous serum, immunoglobulins could be demonstrated by immunofluorescence along the superficial aspect of the epithelial cells; gamma gamma $_{1 \mathrm{a}}$ globulin were thus identified in sections from four patients, and gamma ${ }_{2}$ globulin could be demonstrated in three (Figure 5). However, when the sera from four of the control patients were incubated with their autologous jejunal sections, a similar superficial localization of immunoglobulin was observed; gamma ${ }_{\mathbf{I M}}$ globulin was thus identified in three subjects, gamma $1 \mathrm{a}$ globulin in two, and gamma 2 globulin in one.

When the sera from ten celiac patients and from six additional normal control subjects were incubated with jejunal sections from one of the celiac patients (P.T., blood group $\mathrm{O}, \mathrm{Rh}^{+}$), gamma $_{\text {IM }}$ globulin was demonstrated in all instances in the same superficial location, and gamma $_{1 a}$ globulin was similarly demonstrated in one instance. In these studies, unfixed tissue sections proved to be most satisfactory. As noted previously, when tissue sections were stained directly without preincubation with serum, immunoglobulins were not observed in the superficial epithelial cells. Dilution of the fluoresceinated antibodies with their corresponding unconju- 
gated antisera usually, but not always, inhibited the fluorescence.

The distribution of immunoglobulin in these sections preincubated with serum corresponded to that of beta $_{1 \mathrm{c}} /$ beta $_{1 \mathrm{a}}$ globulin, although their staining was generally less intense and more prominent in the crypt epithelium. Thus, it is probable that immunoglobulins from all sera, especially gamma $_{\text {IM }}$ macroglobulin, are nonspecifically absorbed or fixed to the superficial aspect of mucosal epithelial cells of either autologous or homologous small intestine. No difference could be observed between sera from treated or untreated celiac patients, or control subjects.

\section{Discussion}

The hypothesis that immunologic processes play a role in the pathogenesis of adult celiac disease was investigated by tissue immunofluorescent techniques. The distribution of immunoglobulins, the reaction of dietary antigens including gliadin, and the fixation of complement were thus studied in the jejunal mucosa of patients with adult celiac disease and in control subjects.

Tissue-bound immunoglobulins have been demonstrated in the lesions of diseases thought to be immunological in nature, such as experimental nephritis, experimental serum sickness, the arthus phenomenon, lupus erythematosus, glomerulonephritis, amyloidosis, rheumatic fever, rheumatoid arthritis, and polyarteritis (26-30). In the jejunal mucosa of patients with adult celiac disease, as well as in controls, immunoglobulins were confined to mononuclear cells of the lamina propria. Gamma ${ }_{1 a}$ globulin was the major immunoglobulin identified in these cells. The antigens to which these immunoglobulins were directed could not be identified; gliadin did not react with these immunoglobulins.

Antigen-antibody complexes as well as denatured gamma globulin aggregates may fix complement (31). Complement, bound in vivo, has been identified in the lesions of lupus and experimental nephritis, serum sickness, the arthus phenomenon, glomerulonephritis, amyloidosis, polyarteritis, and acute rheumatic fever (22, 32-35). Moreover, the binding of complement in vitro has been used to localize antigen-antibody complexes or gamma globulin aggregates in the lesions of experimental nephritis, glomerulonephritis, amy- loidosis, and myasthenia gravis (35-38). The distribution of the beta ${ }_{1 \mathrm{c}} /$ beta $_{1 \mathrm{a}}$ globulin component of complement was studied in jejunal mucosa from adult celiac patients and controls. No evidence either for in vivo or for specific in vitro complement fixation, and thus no evidence for the presence of complement-fixing antigen-antibody complexes, was found. The nonspecific fixation of the beta $a_{1}$ globulin component of complement at the superficial margins of the epithelial cells may have masked specific fixation in the case of the celiac patients, but the failure to demonstrate immunoglobulins at that site makes this possibility unlikely.

Since denatured gamma globulin aggregates may fix complement (31), the nonspecific in vitro fixation of the beta 1 globulin component of complement along the superficial margin of the epithelial cells could possibly be secondary to the nonspecific in vitro fixation of immunoglobulins, which was also found to occur in these same areas.

Malik and associates (21) found that fresh serum from five untreated celiac patients reacted with the epithelial cell cytoplasm of unfixed autologous or homologous jejunal mucosa to a significantly greater degree than did the sera from celiac patients on a gluten-free diet, or from normal subjects. They used a fluoresceinated antiserum to the human alpha and beta globulins; antibody to the beta $_{1 \mathrm{c}}$ globulin component of complement and to gamma ${ }_{I M}$ globulin may have been present also in this antiserum. In the present studies, using fluoresceinated antisera to each immunoglobulin as well as to beta $\mathrm{1c}_{1 \mathrm{c}} /$ beta $_{1 \mathrm{a}}$ globulin, absorption or fixation of gamma ${ }_{\mathbf{I M}}$ globulin and the beta $a_{1 c} /$ beta $_{1 a}$ globulin component of complement to the superficial aspect of epithelial cells was observed. This reaction was noted when autologous or homologous unfixed sections were preincubated with fresh sera, either from celiac patients or from control subjects. Since this reaction between gamma ${ }_{\mathbf{I M}}$ macroglobulin and intestinal mucosa was demonstrated with both autologous and blood group $\mathrm{O}$ homologous intestine, it would not appear to involve the blood group antigens that are present in the intestinal mucosa (39).

Thus, although immunoglobulins were found to be present in jejunal mucosa from patients with adult celiac disease, neither immunoglobu- 
lins reacting with gliadin nor complement-fixing immune complexes were identified. Furthermore, a humoral autoantibody directed against intestinal mucosa could not be demonstrated in sera from celiac patients. Therefore, these studies give no support to the immunologic theory of the etiology of adult celiac disease. They cannot exclude the possibility that immunologic processes do play a role in its pathogenesis.

In studies using fluoresceinated antigliadin antibody, epithelium of celiac patients bound gliadin in vitro; no immunoglobulins were found at the same site. Atrophic mucosa from untreated patients and mucosa from treated patients that appeared normal or almost normal on light microscopy demonstrated the same reaction. In three of the celiac patients, gliadin or a derivative seemed to have been bound to the epithelium in vivo; this phenomenon was attributed to dietary gliadin, although one patient denied ingesting gliadin-containing foods. This gliadin binding by the celiac mucosa suggests an inherent abnormality in the intestinal epithelial cell of the celiac patient. The nature of this binding and its significance in the pathogenesis of the disease are not known.

\section{Summary}

To investigate the possible role of immunologic processes in the pathogenesis of adult celiac disease, duodenal and/or jejunal biopsies from nine patients with adult celiac disease and from five control patients were studied by immunofluorescent techniques. The following observations were made :

1) Immunoglobulins were demonstrated in mononuclear cells in the lamina propria of all tissue sections. Gamma ${ }_{1 a}$ globulin was found to be the major immunoglobulin present, but gamma globulin and gamma ${ }_{\mathbf{I M}}$ globulin were similarly identified. These immunoglobulins did not react with gliadin.

2) No in vivo or specific in vitro fixation of the beta ${ }_{1 \mathrm{e}}$ globulin component of complement was observed in these tissues; thus, neither complement-fixing antigen-antibody complexes nor gamma globulin aggregates could be identified. In specimens from all subjects, the beta ${ }_{1 \mathrm{c}}$ globulin component of complement was fixed in vitro at the superficial margin of the epithelial cells and in goblet cells, a distribution corresponding to that of mucin. This nonspecific complement fixation may be secondary to a nonspecific in vitro fixation of immunoglobulin, particularly gamma ${ }_{\text {IM }}$ globulin, which was also observed to be fixed in the same areas.

3) Autoantibodies reactive against epithelial cell cytoplasm could not be demonstrated in the sera from celiac patients.

4) The cytoplasm of the intestinal epithelium from celiac patients bound gliadin, but not casein, bovine serum albumin, or ovalbumin. Only one of the five control patients bound gliadin minimally. The nature and significance of the binding are not known.

\section{References}

1. Van de Kamer, J. H., H. A. Weijers, and W. K. Dicke. Coeliac disease IV. An investigation into the injurious constituents of wheat in connection with their action on patients with coeliac disease. Acta paediat. (Uppsala) 1953, 42, 223.

2. Alvey, C., C. M. Anderson, and M. Freeman. Wheat gluten and coeliac disease. Arch. Dis. Childh. 1957, 32, 434.

3. Kowlessar, O. D., and M. H. Sleisenger. The role of gliadin in the pathogenesis of adult celiac disease. Gastroenterology 1963, 44, 357.

4. Benson, G. D., O. D. Kowlessar, and M. H. Sleisenger. Adult celiac disease with emphasis upon response to the gluten-free diet. Medicine (Baltimore) 1964, 43, 1 .

5. Bayless, T. M., J. H. Yardley, J. H. Norton, and T. R. Hendrix. Adult celiac disease; rapid sequential changes in jejunal mucosa with alterations of dietary gluten. J. clin. Invest. 1962, 41, 1344.

6. Rubin, C. E., L. L. Brandborg, A. L. Flick, P. Phelps, C. Parmentier, and S. van Niel. Studies of celiac sprue III. The effect of repeated wheat instillation into the proximal ileum of patients on a gluten free diet. Gastroenterology 1962, 43, 621.

7. Frazer, A. C., R. F. Fletcher, C. A. C. Ross, B. Shaw, H. G. Sammons, and R. Schneider. Gluten-induced enteropathy. The effect of partially digested gluten. Lancet 1959, 2, 252.

8. Krainich, H. G., and G. Mohn. Further investigations on the toxic effect of wheat flour in celiac disease. 2. Effect of the enzymatic by-products of gliadin. Helv. paediat. Acta 1959, 14, 124.

9. Van Roon, J. H. and A. J. Ch. Haex, W. A. Seeder, and J. de Jong. Clinical and biochemical analysis of gluten-toxicity-No. 11. Clinical experiments on patients suffering from idiopathic steatorrhea after the administration of bromine treated performic acid oxidized polypeptides originating from wheat gluten. Gastroenterologia (Basel) 1960, 94, 227.

10. Messer, M., C. M. Anderson, and R. R. W. Townley. Peptidase activity of biopsies of the duodenal mu- 
cosa of children with and without coeliac disease. Clin. chim. Acta 1961, 6, 768.

11. Isselbacher, K. J. Personal communication.

12. Lepore, M. J. Long-term or maintenance adrenal steroid therapy in nontropical sprue. Amer. J. Med. 1958, 25, 381.

13. Krainich, H. G., F. Debatin, E. Gautier, R. Tobler, and J. A. Velasco. Additional research on the injurious effect of wheat flour in celiac disease. I. Acute gliadin reaction (gliadin shock). Helv. paediat. Acta 1958, 13, 432.

14. Berger, E. Allergic pathogenesis of celiac disease with studies of the splitting up of pathogenic antigens by enzymes. Bibl. paediat. (Basel) (suppl.) 1958, 67, 1.

15. Heiner, D. C., M. E. Lahey, J. F. Wilson, J. W. Gerrard, H. Shwachman, and K. T. Khaw. Precipitins to antigens of wheat and cow's milk in celiac disease. J. Pediat. 1962, 61, 813.

16. Alarcón-Segovia, D., T. Herskovic, K. G. Wakim, P. A. Green, and H. H. Scudamore. Presence of circulating antibodies to gluten and milk fractions in patients with nontropical sprue. Amer. J. Med. 1964, 36, 485.

17. Taylor, K. B., S. C. Truelove, D. L. Thomson, and R. Wright. An immunological study of coeliac disease and idiopathic steatorrhoea: serological reactions to gluten and milk proteins. Brit. Med. J. 1961, 2, 1727.

18. Taylor, K. B., S. C. Truelove, and R. Wright. Serologic reactions to gluten and cow's milk proteins in gastrointestinal disease. Gastroenterology 1964, 46, 99.

19. Huizenga, K. A., E. E. Wollaeger, P. A. Green, and B. F. McKenzie. Serum globulin deficiencies in non-tropical sprue, with report of two cases of acquired agammaglobulinemia. Amer. J. Med. 1961, 31, 572.

20. Biserte, G., R. Havez, O. Dubois, and R. Dubois. L'intolérance au gluten dans la maladie coeliaque "allergie" ou "déficit enzymatique"? Lillie méd. 1958, 3, 729.

21. Malik, G. B., W. C. Watson, D. Murray, and B. Cruickshank. Immunofluorescent antibody studies in idiopathic steatorrhoea. Lancet 1964, 1, 1127.

22. Lachmann, P. J., H. J. Müller-Eberhard, H. G. Kunkel, and F. Paronetto. The localization of in vivo bound complement in tissue sections. J. exp. Med. 1962, 115, 63.

23. Flick, A. L., W. E. Quinton, and C. E. Rubin. A peroral hydraulic biopsy tube for multiple sampling at any level of the gastrointestinal tract. Gastroenterology 1961, 40, 120.

24. Burkholder, P. M., A. H. Littell, and P. G. Klein. Sectioning at room temperature of unfixed tissues, frozen in a gelatin matrix, for immunohistologic procedures. Stain Technol. 1961, 36, 89.

25. McDevitt, H. O., J. H. Peters, L. W. Pollard, J. G. Harter, and A. H. Coons. Purification and analy- sis of fluorescein-labelled antisera by column chromatography. J. Immunol. 1963, 90, 634.

26. Mellors, R. C., and L. G. Ortega. Analytical pathology III. New observations on the pathogenesis of glomerulonephritis, lipid nephrosis, periarteritis nodosa, and secondary amyloidosis in man. Amer. J. Path. 1956, 32, 455.

27. Vazquez, J. J., and F. J. Dixon. Immunohistochemical study of lesions in rheumatic fever, systemic lupus erythematosus, and rheumatoid arthritis. Lab. Invest. 1957, 6, 205.

28. Dixon, F. J., J. J. Vazquez, W. O. Weigle, and C. G. Cochrane. Pathogenesis of serum sickness. Arch. Path. 1958, 65, 18.

29. Kaplan, M. H., and F. D. Dallenbach. Immunologic studies of heart tissue III. Occurrence of bound gamma globulin in auricular appendages from rheumatic hearts. Relationship to certain histopathologic features of rheumatic heart disease. J. exp. Med. 1961, 113, 1.

30. Cochrane, C. G., W. O. Weigle, and F. J. Dixon. The role of polymorphonuclear leukocytes in the initiation and cessation of the arthus vasculitis. J. exp. Med. 1959, 110, 481.

31. Ishizaka, T., and K. Ishizaka. Biological activities of aggregated gamma globulin. 1. Skin reactive and complement-fixing properties of heat denatured gamma globulin. Proc. Soc. exp. Biol. (N. Y.) 1959, 101, 845.

32. Freedman, P., and A. S. Markowitz. Gamma globulin and complement in the diseased kidney. J. clin. Invest. 1962, 41, 328.

33. Dixon, F. J. The role of antigen-antibody complexes in disease. Harvey Lect. 1962-1963, series 58.

34. Cochrane, C. G. Studies on the localization of circulating antigen-antibody complexes and other macromolecules in vessels 1 . Structural studies. J. exp. Med. 1963, 118, 489.

35. Unanue, E., and F. J. Dixon. Experimental glomerulonephritis IV. Participation of complement in nephrotoxic nephritis. J. exp. Med. 1964, 119, 965.

36. Vogt, A., and H. G. Kochem. Histo-serologische untersuchungen mit fluoresceinmarkiertem antikomplement. Z. Zellforsch. 1960, 52, 640.

37. Strauss, A. J. L., B. C. Seegal, K. C. Hsu, P. M. Burkholder, W. L. Nastuk, and K. E. Osserman. Immunofluorescence demonstration of a muscle binding, complement fixing serum globulin fraction in myasthenia gravis. Proc. Soc. exp. Biol. (N. Y.) 1960, 105, 184.

38. Burkholder, P. M. Complement fixation in diseased tissues. 1. Fixation of guinea pig complement in sections of kidney from humans with membranous glomerulonephritis and rats injected with anti-rat kidney serum. J. exp. Med. 1961, 114, 605.

39. Szulman, A. E. The histological distribution of the blood group substances in man as disclosed by immunofluorescence. II. The $\mathrm{H}$ antigen and its relation to A and B antigens. J. exp. Med. 1962, $115,977$. 